\title{
Characterization of a Carbon-Nitrogen Network Solid with NMR and High Field EPR
}

\author{
David Rovnyak, ${ }^{\dagger}$ Marc Baldus,${ }^{\dagger}$ Boris A. Itin, ${ }^{\dagger}$ Marina Bennati, ${ }^{\dagger}$ Andrew Stevens, ${ }^{\dagger}$ and \\ Robert G. Griffin*, \\ MIT/Harvard Center for Magnetic Resonance and Department of Chemistry, \\ Massachusetts Institute of Technology, Cambridge, Massachusetts 02139, and Department of Chemistry, \\ Harvard University, Cambridge, Massachusetts 02139
}

Received: February 2, 2000; In Final Form: July 11, 2000

\begin{abstract}
Considerable attention has been focused on developing a synthetic route to a carbon-nitrogen material with mechanical and thermal properties comparable or superior to those of diamond. To date, no substance with the desired $\mathrm{C}_{3} \mathrm{~N}_{4}$ stoichiometry in a silicon-nitride crystal lattice has been reported. One of the principal difficulties in the pursuit of ultrahard carbon-nitrogen $(\mathrm{CN})$ solids is the characterization of amorphous $\mathrm{CN}$ samples. We describe a solid-state NMR study of a paracyanogen-like solid utilizing ${ }^{13} \mathrm{C}-{ }^{-15} \mathrm{~N}$ adiabatic-passage Hartmann-Hahn cross-polarization (APHH-CP) to perform dipolar filtering and show that this method is well-suited for recoupling ${ }^{13} \mathrm{C}_{-15}{ }^{15} \mathrm{~N}$ in network solids. In addition, high-frequency electron paramagnetic resonance (EPR) indicates a density of electron spins of approximately $1 \times 10^{17} \mathrm{e}^{-} / \mathrm{cm}^{3}$. We conclude by discussing how NMR and EPR data may be useful for optimizing CN-polymer samples as potential precursors for ultrahard carbon nitrogen solids.
\end{abstract}

\section{Introduction}

Modern, high-performance materials are required for applications in computing (heat conduction and insulation), industrial processes (hardness and machinability), and medicine (bioimplants and surgical tools). Examples of synthetic materials that have emerged to address these markets include phosphazenes, synthetic diamonds, boron nitride, and many plastics. A recent approach for the development of new materials is the use of theoretical models to predict, from first principles only, properties of hypothetical solids. It has been proposed that a crystalline solid with $\mathrm{C}_{3} \mathrm{~N}_{4}$ stoichiometry in a $\beta-\mathrm{Si}_{3} \mathrm{~N}_{4}$ crystal lattice would have a bulk modulus comparable or greater to that of diamond, have a high thermal conductivity, and be optically transparent. ${ }^{1-3}$ Synthetic routes aimed at such carbonnitride samples commonly produce amorphous powders or films with few or no crystalline regions. ${ }^{4-10}$ The analysis of amorphous powders is difficult since many techniques such as Rutherford backscattering (RBS), X-ray photoelectron spectroscopy (XPS), and electron energy loss spectroscopy (EELS) probe primarily sample surfaces. While quantitating atom ratios and revealing hybridization, these methods are unable to describe complete local structural motifs of the bulk material.

Solid-state nuclear magnetic resonance (SSNMR) is used in a diverse range of disciplines to characterize local structure in crystalline and amorphous solids. ${ }^{11,12}$ Here, we utilize Blochdecay and cross-polarization experiments, together with the adiabatic passage Hartmann-Hahn cross-polarization (APHH$\mathrm{CP})^{13,14}$ method to transfer polarization between ${ }^{13} \mathrm{C}$ and ${ }^{15} \mathrm{~N}$ nuclei in a paracyanogen-like material. The dipolar filtering of APHH-CP is able to improve resolution, facilitate assignments, and provide connectivity information. It is a principle aim of this study to demonstrate that such information can be obtained

\footnotetext{
* To whom correspondence should be addressed.

MIT/Harvard Center for Magnetic Resonance and Department of Chemistry.

$\doteqdot$ Department of Chemistry, Harvard University.
}

in network solids, where sensitivity is at a premium, without resorting to conventional $2 \mathrm{D}$ chemical shift correlation experiments.

It is of additional interest that network solids can possess significant concentrations of paramagnetic impurities. ${ }^{15,16}$ Spectroscopically, paramagnetic defects may be useful for improving spectral density, for electron paramagnetic resonance (EPR) studies, and as paramagnetic centers to enhance NMR spectra through dynamic nuclear polarization. ${ }^{15,17,18}$ EPR studies at high frequencies $(>100 \mathrm{GHz})$ are attractive since sample sizes are very small and isotopic labeling is not required. We have therefore also acquired $139.5 \mathrm{GHz}$ electron paramagnetic resonance (EPR) spectra for additional insight into paracyanogen-like materials.

\section{Experimental Section}

Sample Preparation. Samples of $\mathrm{K}^{13} \mathrm{C}^{15} \mathrm{~N}$ and $\mathrm{Na}^{13} \mathrm{C}^{15} \mathrm{~N}$ were obtained from Cambridge Isotope Laboratories (Andover, MA 01810) and used without further purification. Preparation of $\mathrm{Hg}(\mathrm{CN})_{2}$ : $\mathrm{HCN}$ was generated by addition of $\mathrm{NaCN}$ or $\mathrm{KCN}$ in aqueous solution to sulfuric acid; the HCN was transferred through a condenser tube into a reaction vessel containing an excess of mercuric oxide, $\mathrm{HgO}$, suspended in water. $\mathrm{Hg}(\mathrm{CN})_{2}$ is very water-soluble and hence the excess $\mathrm{HgO}$ is removed by filtration; subsequent evaporation with heat yields a white powder. $\mathrm{Hg}(\mathrm{CN})_{2}$ is both heat- and light-sensitive. Preparation of paracyanogen-like solid: The $\mathrm{Hg}(\mathrm{CN})_{2}$ was annealed under vacuum and at high temperature; for details see Stevens et al. ${ }^{19}$ Samples were baked at $100{ }^{\circ} \mathrm{C}$ for approximately $12 \mathrm{~h}$ before they were packed into rotors. Caution: Consult your departmental and institutional safety officers before working with HCN.

Nuclear Magnetic Resonance. NMR experiments were performed at room temperature on custom-designed spectrometers operating at $4.8 \mathrm{~T}\left(200 \mathrm{MHz}\right.$ for $\left.{ }^{1} \mathrm{H}\right)$ and $7.4 \mathrm{~T}(317 \mathrm{MHz}$ for $\left.{ }^{1} \mathrm{H}\right)$. Three-channel, custom-designed probes incorporated 


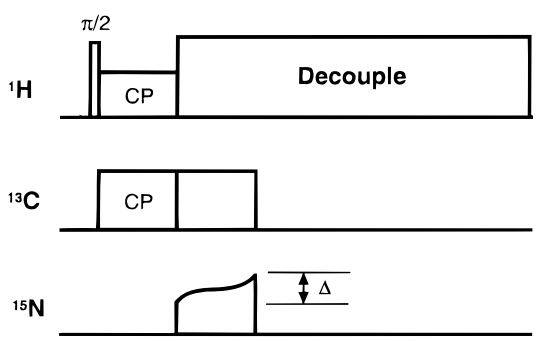

Figure 1. Diagram of the adiabatic passage Hartmann-Hahn crosspolarization pulse sequence, shown here for polarization transfer first from ${ }^{1} \mathrm{H}$ to ${ }^{13} \mathrm{C}$ via conventional cross-polarization followed by $\mathrm{APHH}-$ $\mathrm{CP}$ from ${ }^{13} \mathrm{C}$ to ${ }^{15} \mathrm{~N}$. An even offset profile of at least $10 \mathrm{kHz}$ is obtained when $\Delta=2-3 \mathrm{kHz}$.

5 and $4 \mathrm{~mm}$ Chemagnetics spinner assemblies and implemented transmission line principles to deliver radio frequency power to the coil. The APHH-CP experiment is diagrammed in Figure $1 .^{13,14}$ The value of $\Delta$ in Figure 1 was set in the $2-4 \mathrm{kHz}$ range to provide an even polarization transfer profile of at least \pm 5 kHz. ${ }^{13,14}$ Typical RF fields for cross-polarization and APHH$\mathrm{CP}$ ranged from 30 to $50 \mathrm{kHz}$ depending upon the matching conditions. An ${ }^{15} \mathrm{~N}$-acetyl-valine (NAV) sample was used to set the appropriate RF matching condition for the APHH-CP. Proton decoupling fields of $100 \mathrm{kHz}$ or greater were employed. Magic-angle spinning rates were controlled to within a few hertz, and typical rates used in this study were in the $6-8 \mathrm{kHz}$ range.

All ${ }^{13} \mathrm{C}$ chemical shifts are referenced externally to glycine such that the carbonyl line is defined to be $177 \mathrm{ppm}$. All ${ }^{15} \mathrm{~N}$ chemical shifts are referenced externally to NAV such that the nitrogen shift in ${ }^{15} \mathrm{NH}_{3}$ (1) is defined to be $0 \mathrm{ppm}$.

Electron Paramagnetic Resonance. EPR data were recorded at room and low temperature $(10 \mathrm{~K})$ with a custom-designed pulsed EPR spectrometer operating at $139.5 \mathrm{GHz}(5 \mathrm{~T}) .^{20}$

\section{Results}

For our study of NMR in network-bonded CN solids, we selected a material that is prepared by thermal annealing of mercuric(II) cyanide $\operatorname{Hg}(\mathrm{CN})_{2} \cdot{ }^{21}$ This synthesis was first performed by Guy-Lussac, and the resulting solid is believed to be an amorphous carbon-nitrogen polymer, often denoted paracyanogen $(\mathrm{pCN})$. Paracyanogen has been explored as a precursor for metallic $\mathrm{CN}$ polymers ${ }^{22}$ and ultrahard carbonnitride. ${ }^{19,23}$ A convenient isotopic enrichment method exists for paracyanogen through the synthesis and subsequent annealing of ${ }^{13} \mathrm{C},{ }^{15} \mathrm{~N}$-mercuric cyanide (see Experimental Section for details). Moreover, the structure of paracyanogen has not been demonstrated in the literature, although recent studies have ruled out several proposed models, ${ }^{22,23}$ shown in Figure $2 \mathrm{a}$, and explored the high-temperature and high-pressure phase diagram ${ }^{19}$ of $\mathrm{pCN}$. Structures such as those in Figure 2a are highly ordered, and their extended conjugation would lead to metallic character. ${ }^{22}$ More recently, the structure of Figure $2 b$, which is composed of chains of $\mathrm{sp}^{2}$ carbon and nitrogen with pendant nitriles, was suggested to be more representative of the physical properties of pCN. ${ }^{19,23}$ Two samples were made for this study, denoted $\mathrm{pCN}\left({ }^{13} \mathrm{C}\right)$ and $\mathrm{pCN}\left({ }^{13} \mathrm{C},{ }^{15} \mathrm{~N}\right) \cdot \mathrm{pCN}\left({ }^{13} \mathrm{C}\right)$ is a fine, black powder and was generated by high-temperature, vacuum annealing of $25 \%-{ }^{13} \mathrm{C}, \mathrm{Hg}(\mathrm{CN})_{2}$. The second sample, pCN$\left({ }^{13} \mathrm{C},{ }^{15} \mathrm{~N}\right)$, was generated by annealing of $100 \%-{ }^{15} \mathrm{~N}, 25 \%-{ }^{13} \mathrm{C}$, $\mathrm{Hg}(\mathrm{CN})_{2}$.

Nuclear Magnetic Resonance. In Figure 3 we show ${ }^{13} \mathrm{C}$ echo-detected CP-MAS spectra of $\mathrm{pCN}\left({ }^{13} \mathrm{C}\right)$ obtained at 4.8 and 7.4 T. Figure 3 exhibits lines at 163 and 157 ppm as well as a broad feature at $120 \mathrm{ppm}$. There are no lines in the $\mathrm{sp}^{3}$ region a)
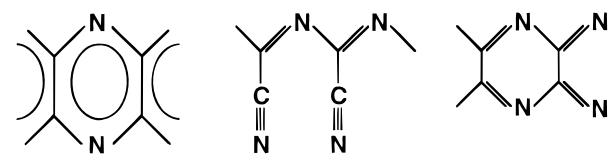

b)

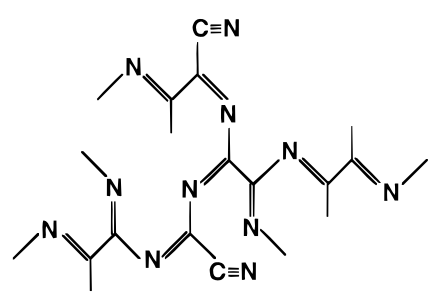

Figure 2. (a) Chemical structures proposed for paracyanogen that possess a high degree of order and extended conjugation; (b) amorphous chains of $\mathrm{sp}^{2}$ carbon and nitrogen with pendant nitriles proposed ${ }^{23,37}$ to explain the low order and electrically insulating nature of paracyanogen.

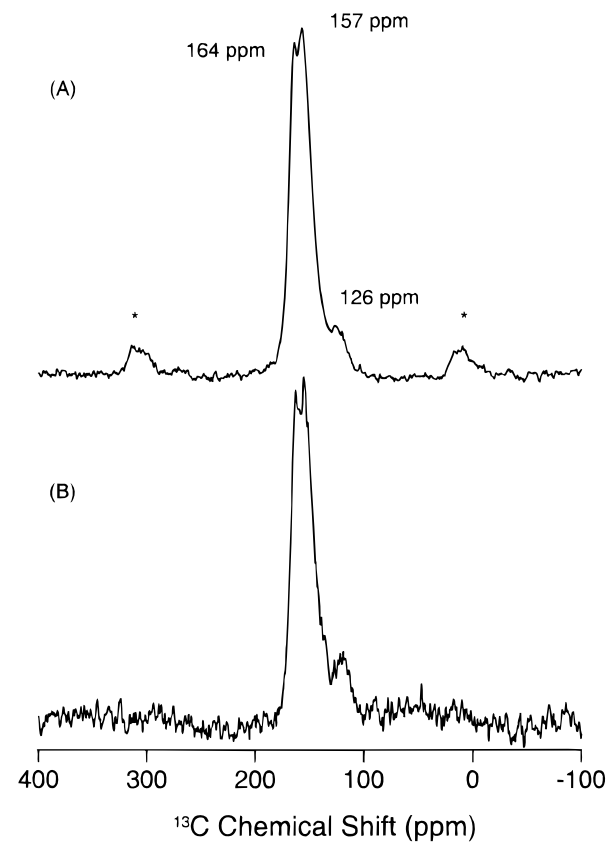

Figure 3. Echo-detected ${ }^{13} \mathrm{C}$ cross-polarization spectra of $\mathrm{pCN}\left({ }^{13} \mathrm{C}\right)$ with proton decoupling at (A) $4.8 \mathrm{~T}\left(\omega_{0} / 2 \pi\left[{ }^{13} \mathrm{C}\right]=50 \mathrm{MHz}\right)$ and (B) $7.4 \mathrm{~T}\left(\omega_{0} / 2 \pi\left[{ }^{13} \mathrm{C}\right]=80 \mathrm{MHz}\right)$. Asterisks denote spinning sidebands. Recycle times were 4 and $8 \mathrm{~s}(4.8 \mathrm{~T}, 7.4 \mathrm{~T})$. The spectra are referenced to an external glycine sample.

(0-70 ppm). The lines at 163 and $157 \mathrm{ppm}$ correspond to $\mathrm{sp}^{2}$ carbon, while the broad $120 \mathrm{ppm}$ resonance is assigned to nitrile groups. The ${ }^{13} \mathrm{C}$ chemical shift in nitriles is very sensitive to local structure, and hence this feature experiences considerable amorphous broadening. Increasingly longer recycle delays were required at 7.4 and $9.4 \mathrm{~T}(15-20 \mathrm{~s}$ recycle times; data not shown), suggesting a sharply declining spectral density. We were unable to obtain useful spectra at $14.1 \mathrm{~T}$ and attribute this to low spectral density. The spectral resolution is only slightly improved at 7.4 T, indicating at least partial amorphous character of this solid. Asymmetric doublets for spin-1/2 nuclei coupled to quadrupolar nuclei are most readily observed for ${ }^{13} \mathrm{C}$ resonances in nitrile groups; ${ }^{24}$ however, the nitrile region is too broad to observe this effect in our spectra. The ${ }^{13} \mathrm{C}$ line widths of $\mathrm{pCN}\left({ }^{13} \mathrm{C}\right)$ and $\mathrm{pCN}\left({ }^{13} \mathrm{C},{ }^{15} \mathrm{~N}\right)$ are also not measurably different. This is reasonable considering that asymmetric splitting was not observed in ${ }^{29} \mathrm{Si}$ spectra of $\beta-\mathrm{Si}_{3} \mathrm{~N}_{4} \cdot{ }^{25}$

It is remarkable that the ${ }^{1} \mathrm{H}$ cross-polarization experiment can be applied as this sample is expected to be aprotic. To better 


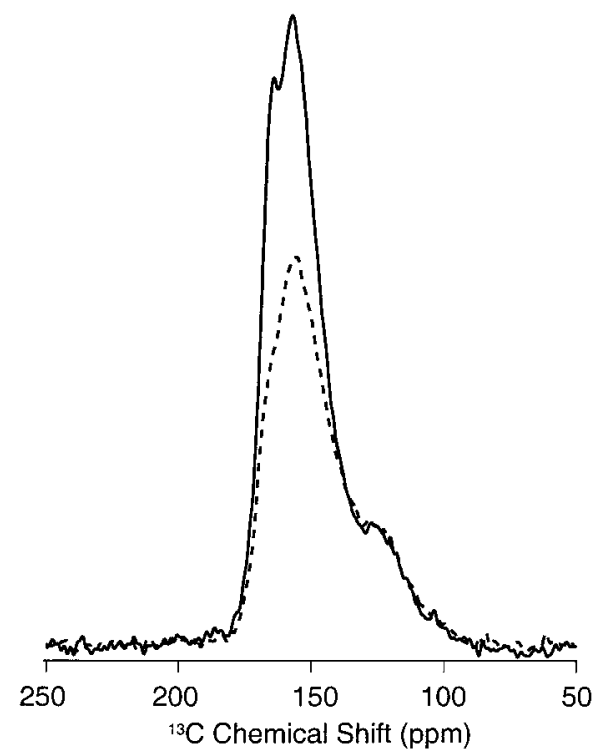

Figure 4. Echo-detected ${ }^{13} \mathrm{C}$ MAS NMR spectra of $\mathrm{pCN}\left({ }^{13} \mathrm{C}\right)$ via direct-excitation (dashed trace) and cross-polarization (solid trace). Spectra have been normalized to the broad feature at $120 \mathrm{ppm}$ to emphasize the relative excitation efficiencies.

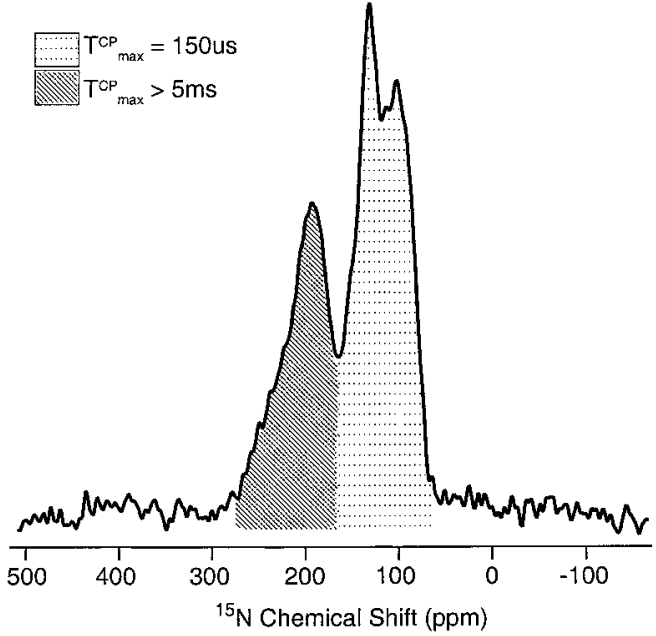

Figure 5. Echo-detected ${ }^{15} \mathrm{~N}$ cross-polarization MAS spectra with proton decoupling of $\mathrm{pCN}\left({ }^{13} \mathrm{C},{ }^{15} \mathrm{~N}\right)$ at $4.8 \mathrm{~T} ; 1440$ transients were collected with a recycle time of $5 \mathrm{~s}$. MAS frequency was $7.9 \mathrm{kHz}$.

understand this behavior, we compare the ${ }^{13} \mathrm{C}$ echo-detected spectra of $\mathrm{pCN}\left({ }^{13} \mathrm{C}\right)$ obtained via cross-polarization and onepulse excitation, as shown in Figure 4. The spectra are normalized arbitrarily to the broad $120 \mathrm{ppm}$ feature to facilitate their comparison. The differing excitation profiles suggest that the line at $163 \mathrm{ppm}$ is more strongly coupled to the proton bath than the $157 \mathrm{ppm}$ line due to its enhanced relative intensity in the $\mathrm{CP}$ spectra. We also performed a $\mathrm{CP}$ build-up experiment in which the intensity of the ${ }^{13} \mathrm{C} \mathrm{CP}$-MAS signal is monitored as a function of the contact time. The build-up of the CP signal intensity corresponded to a time constant of $T_{\mathrm{r}}=0.17 \mathrm{~ms}$, indicating that the observed resonances do not correspond to ${ }^{13} \mathrm{C}$ 's with directly bound ${ }^{1} \mathrm{H}$ 's. ${ }^{26,27}$ The proton decoupling strength was approximately $100 \mathrm{kHz}$, which is sufficient to completely remove any ${ }^{1} \mathrm{H}-{ }^{13} \mathrm{C}$ dipolar couplings not averaged by MAS in the ${ }^{13} \mathrm{C}$ spectra.

A typical ${ }^{15} \mathrm{~N}$ CP spectrum is shown in Figure 5. Resonances are observed at 101, 130, and $191 \mathrm{ppm}$, along with a broad shoulder at $252 \mathrm{ppm}$. The ${ }^{15} \mathrm{~N}$ CP-MAS spectrum is clearly richer than the ${ }^{13} \mathrm{C}$ spectra obtained either by cross-polarization

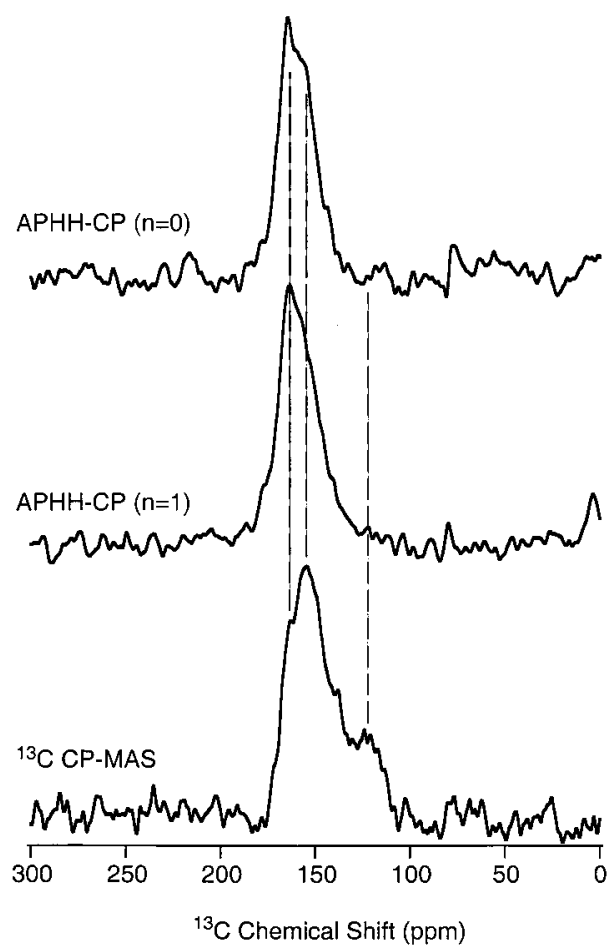

Figure 6. ${ }^{13} \mathrm{C}$-detected $\mathrm{APHH}-\mathrm{CP}$ at $4.8 \mathrm{~T}$, as per the pulse sequence of Figure 1 modified for initial $\mathrm{CP}$ from ${ }^{1} \mathrm{H}$ to ${ }^{13} \mathrm{C}$ followed by APHH$\mathrm{CP}$ from ${ }^{13} \mathrm{C}$ to ${ }^{15} \mathrm{~N}$. The mechanism for coherence transfer is determined by the parameter $n$ in the APHH-CP matching condition, where a value of 0 permits both proton driven spin diffusion and $J$-coupled transfer, and $n= \pm 1$ allows only for dipolar coherence transfer.

or direct excitation. From ${ }^{15} \mathrm{~N}$ NMR spectroscopy in silicon nitrides and other nitrogen ceramics, ${ }^{25,28}$ this sensitivity of the ${ }^{15} \mathrm{~N}$ shifts is expected. From an ${ }^{15} \mathrm{~N} \mathrm{CP}$ rise-time experiment, it was found that the upfield portion of the ${ }^{15} \mathrm{~N}$ spectrum $(130$ ppm, $101 \mathrm{ppm})$ reaches its maximum intensity at about $150 \mu \mathrm{s}$, but the downfield portion (252 ppm, $191 \mathrm{ppm}$ ) continues to increase in signal after $5 \mathrm{~ms}$. Therefore, the upfield portion of the spectrum corresponds to nitrogen nuclei with directly bonded protons, whereas the downfield portion is coupled very weakly to the proton bath. This is illustrated by the shaded regions in Figure 5. From Figure 5, it is possible to identify regions corresponding to imine (191 ppm), secondary amine (130 ppm, $101 \mathrm{ppm})$, and nitrile (252 ppm) groups.

Dipolar recoupled spectra employing the APHH-CP sequence are shown for ${ }^{15} \mathrm{~N}$ to ${ }^{13} \mathrm{C}$ transfer and ${ }^{13} \mathrm{C}$ to ${ }^{15} \mathrm{~N}$ transfer in Figures 6 and 7, respectively. The pulse sequence of Figure 1 was employed, in which, in each case, initial magnetization was prepared with cross-polarization from protons. The APHH-CP experiments are shown for $n=1$ and $n=0$ matching conditions for the middle and top spectra, respectively. The signal-to-noise in the spectra ranges from 10 to $10^{2}$, each spectrum requiring approximately $12 \mathrm{~h}$ of acquisition time. The coherence transfer observed in the $n=0$ cases probably occurs via proton-proton spin flips and not via the $J$-coupling. For example, signal is observed in Figure $7(n=0)$ for the secondary amines, for which one bond ${ }^{13} \mathrm{C}-{ }^{15} \mathrm{~N} J$-couplings are of the order of $10 \mathrm{~Hz}$, but scalar transfer is expected in the nitrile and imino regions (252 ppm,191 ppm) of the ${ }^{15} \mathrm{~N}$-detected APHH-CP spectrum since these groups will have the largest ${ }^{13} \mathrm{C}-{ }^{15} \mathrm{~N}$ one-bond $J$-couplings. Mixing times up to $7 \mathrm{~ms}$ were employed in an attempt to observe scalar transfer, but this was unsuccessful. Probably even longer contact times are needed as well as a higher enrichment of ${ }^{13} \mathrm{C}$ (25\% in this study). However the $n=1{ }^{15} \mathrm{~N}$-detected APHH$\mathrm{CP}$ spectrum provides crucial information for resolving sites 


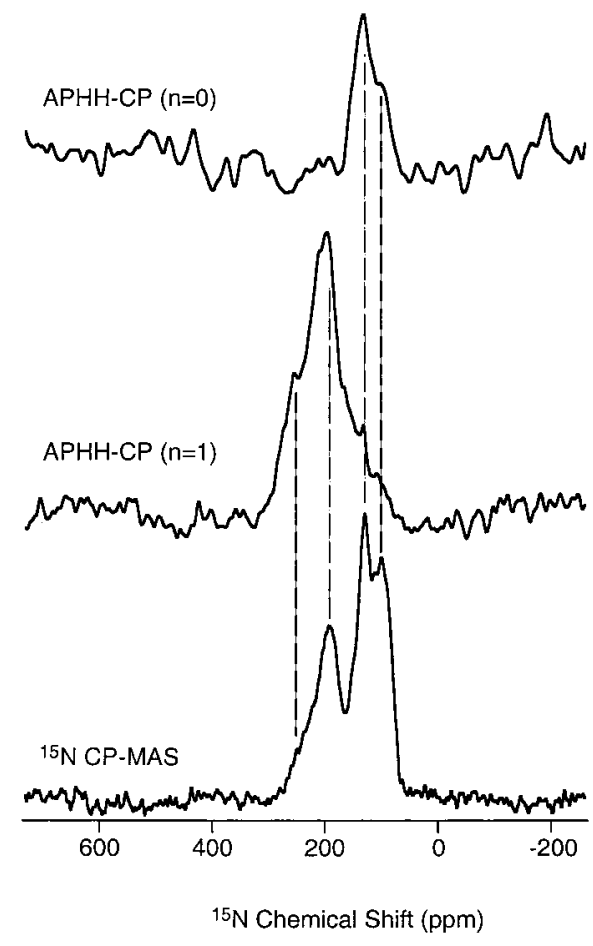

Figure 7. ${ }^{15} \mathrm{~N}$-detected $\mathrm{APHH}-\mathrm{CP}$ at $4.8 \mathrm{~T}$ using the pulse sequence of Figure 1. The matching conditions $n$ are marked on the figure; see text and Figure 6 caption for more discussion.

and improving assignments. The downfield shoulder of the ${ }^{15} \mathrm{~N}$ $\mathrm{CP}$ spectrum is resolved at $252 \mathrm{ppm}$ in the APHH-CP $(n=1)$, consistent with typical nitrile shifts and with an increased intensity relative to the $191 \mathrm{ppm}$ resonance that is to be expected from the larger ${ }^{13} \mathrm{C}-{ }^{15} \mathrm{~N}$ dipolar coupling of the nitrile as compared to the imine. The relative transfer efficiencies in the upfield region (130 ppm, $101 \mathrm{ppm})$ suggest a stronger $\mathrm{CN}$ interaction at $130 \mathrm{ppm}$ than at $101 \mathrm{ppm}$. Assignments will be treated in more detail in the discussion.

Electron Paramagnetic Resonance. Direct-excitation ${ }^{15} \mathrm{~N}$ NMR spectra could not be obtained due to the presence of intense, short- $\mathrm{T}_{2}$ signals that introduced large distortions in the spectra. This may be attributed to paramagnetic nitrogens, which are expected in lattice defects when a nitrogen atom occupies a carbon position or when a polymer segment terminates with a divalent nitrogen. We have confirmed the existence of paramagnetic centers with EPR experiments obtained at 139.5 $\mathrm{GHz}$, shown in Figure 8. A single absorption is observed at room and low temperature $(10 \mathrm{~K})$. The low-temperature spectrum, obtained by integrating the spin-echo intensity over the magnetic field sweep, gives an absorptive line shape as shown in Figure 8. The signal in this sample only permitted continuous wave EPR (CW-EPR) at room temperature, which results in a derivative spectrum (inset of Figure 8). A field sweep range of $0.5 \mathrm{~T}$ (about the central field of $5 \mathrm{~T}$ ) allows detection of paramagnetic centers with $g$-values of 2.15-1.85.

The line shape is only slightly asymmetric, indicating a small $g$-anisotropy with an estimated isotropic $g$-value of 2.0032 . Magnetic field scans over half a Tesla detected no other paramagnetic signals, suggesting that other impurities are not present. The EPR signal intensity increases at lower temperature in a Boltzmann-like fashion as expected for an isolated paramagnetic center in an electrically insulating material. Without knowing the molecular unit of this material, it is difficult to specify the spin density; however, the spin-echo intensity was compared to standard solutions of different organic radicals, indicating an approximate spin count of $1 \times 10^{17}$

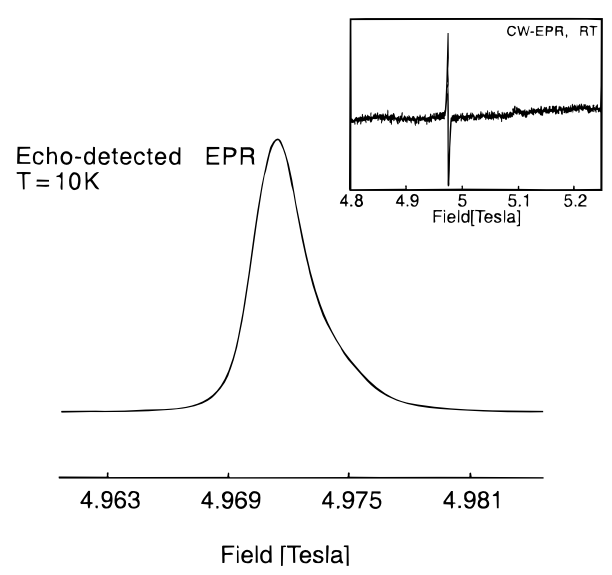

Figure 8. A $140 \mathrm{GHz}$ EPR spectrum (main) obtained by integration of the spin-echo intensity over the field sweep at $10 \mathrm{~K}$. A sweep of 0.5 $\mathrm{T}$ at room temperature is shown in the inset. The $g$-anisotropy is small, and $g_{\text {iso }}=2.0032$.

$\mathrm{e}^{-} / \mathrm{cm}^{3}$. EPR spectra for $\mathrm{pCN}\left({ }^{13} \mathrm{C}\right)$ and $\mathrm{pCN}\left({ }^{13} \mathrm{C},{ }^{15} \mathrm{~N}\right)$ are identical. Additionally, the observation of spin-echoes at low temperature indicates that electron-nuclear double-resonance (ENDOR) experiments, which detect electron-nuclear dipolar couplings, are possible. It is also noted that dynamic nuclear polarization (DNP) experiments may be useful to enhance the NMR spectra and possibly gain insight into which species are more proximate to paramagnetic impurities; however, this was beyond the scope of the present study.

\section{Discussion}

Materials that exhibit covalent, high-dimensional bonding may be aprotic and amorphous, and these characteristics can significantly affect the acquisition of NMR spectra. Recycle times up to an hour or longer may be required ${ }^{25,28,29}$ due to the near absence of local motions in the NMR time scale, or amorphous broadening ${ }^{16,30,31}$ could limit site resolution to the point that some materials cannot even be described by repeated structural units.

Thus, the observation of resolved resonances in the ${ }^{13} \mathrm{C}$ and ${ }^{15} \mathrm{~N}$ NMR spectra (Figures 3 and 5) indicates that this $\mathrm{pCN}$ like material is composed of a repeated structural motif. However, the degree of order is insuffient to provide NMR line widths normally observed for crystalline phase samples or to motionally constrain the solid since NMR recycle times of 3-5 $\mathrm{s}$ provide good signal-to-noise at $4.7 \mathrm{~T}$. This disparity is reconciled first by our knowledge of paramagnetic centers and $\mathrm{NH}$ moieties whose motions may provide frequencies on the NMR time scale. Second, we note that field-dependent studies show a rapidly declining spectral density at higher static fields, indicating some degree of extended, three-dimensional bonding in this solid. An explanation consistent with these findings is that a repeated, two-dimensional structural unit exists along with significant covalent cross-linking, which constrains motions and introduces structural heterogeneity. Given the low concentration of paramagnetic defects and the use of echo-detection we believe that we are observing signals of spins in the bulk material and not spins that are proximate to a minority phase or defect. A study of the phase properties of an identically prepared material also gave no evidence of minority phases in thermally annealed pCN. ${ }^{19}$

The current data is insufficient to fully constrain the local structure of this solid; however, we are able to make assignments of the spectra to chemical moieties, and we discuss their significance here. From the ${ }^{13} \mathrm{C}$ spectra, we rule out the presence 
of $\mathrm{sp}^{3}$ carbon and identify two $\mathrm{sp}^{2}$ carbon lines and a broad nitrile resonance. This observation agrees with previous hypotheses for the structure of paracyanogen-like solids ${ }^{23}$ that describe chains of $\mathrm{sp}^{2}$ carbon and nitrogen with cyano groups hanging off the chains. The absence of $\mathrm{sp}^{3}$ carbon indicates that water molecules do not add across double bonds, an effect seen in paracyanogen-like solids prepared by reactive sputtering ${ }^{23}$ and also in protonated silicon nitride powders. ${ }^{29}$ Other studies have observed that reactive sputtering leads to dangling bonds on carbon nuclei, which are reactive centers for water addition reactions. ${ }^{16}$ In contrast, our sample was prepared by a thermal annealing process. Although samples were stored in air before measuring, controlled exposures to moisture were not undertaken. The addition of water in this fashion would result in protons dipolar coupled to $\mathrm{sp}^{3}$ carbon nuclei, which would thus be easily detected in CPMAS spectra. The $\mathrm{sp}^{2}$ chemical shifts agree with imine resonances observed in nitrogenated amorphous $\mathrm{C}: \mathrm{H}$ films. ${ }^{32}$ It is also significant that the difference in chemical shift between the two $\mathrm{sp}^{2}$ carbon species is wellresolved $(5 \mathrm{ppm})$. A distribution of carbon bound to one, two, or three nitrogens, or one or more cyano groups, would be expected to result in a completely amorphous spectrum. This reinforces our assertion above that resolved lines must indicate the existence of a regular chemical unit. Finally, a broad signal is present at about $120 \mathrm{ppm}$, consistent with literature values for nitrile groups. ${ }^{33}$

Turning to the nitrogen spectra, a nitrile region at $252 \mathrm{ppm}$ is resolved by correlating the ${ }^{15} \mathrm{~N}-\mathrm{CPMAS}$ spectrum with the APHH-CP $(n=1)$ spectrum, as shown in Figure 7. Without the ${ }^{13} \mathrm{C}-{ }^{15} \mathrm{~N}$ correlation to resolve the cyano region, this assignment would be difficult as the signal at $252 \mathrm{ppm}$ is weak. In fact, the weak polarization of the cyano region in the ${ }^{15} \mathrm{~N}$ CPMAS spectrum probably explains the absence of intensity for the nitrile region in the ${ }^{13} \mathrm{C}$-detected APHH-CP (Figure 5, $n=1)$. We assign the $191 \mathrm{ppm}{ }^{15} \mathrm{~N}$ region to imine groups $(\mathrm{C}=\mathrm{N}-\mathrm{R})$ based on the large intensity of the peak in the APHH$\mathrm{CP}(n=1)$, which suggests strong $\mathrm{CN}$ dipolar coupling, and the chemical shift that is well outside the nitrile and amino regions. The imino region may be broadened by heterogeneity in $\mathrm{R}$, which may be $\mathrm{C}$ or $\mathrm{N}$, but is still well-resolved from the secondary amine groups at 130 and $101 \mathrm{ppm}$, which are typical for $\mathrm{R}^{*} \mathrm{NHR}$ shifts. ${ }^{33}$ Here we propose to assign these to $\mathrm{C}^{*} \mathrm{NHC}$ and $\mathrm{C}^{*} \mathrm{NHN}$ moieties respectively because their intensities are similar in CPMAS spectra but differ by a factor of 2 in the APHH-CP. This is reasonable considering that the adiabatictransfer efficiency should be identical for both sites due to the even offset profile of APHH-CP ${ }^{14}$ and the small difference in isotropic shifts. A significant observation is that the breadth of the imine region and the presence of two distinct amine resonances both suggest $\mathrm{N}-\mathrm{N}$ bonding, a feature that is absent from Figure $2 \mathrm{~b}$. The presence of $\mathrm{N}-\mathrm{N}$ bonding has also been supported by thermal decomposition studies. ${ }^{19}$

The APHH-CP spectra provide dipolar filtering information that improves resolution and facilitates assignments, as in the case of the nitrile region which is resolved at $252 \mathrm{ppm}$ in Figure $7(n=1)$. However, in the $n=0$ case, the ${ }^{15} \mathrm{~N}$-detected APHH$\mathrm{CP}$ experiment suggests scalar carbon-to-nitrogen transfer for the secondary amines which is clearly not physical based on typical $J_{\mathrm{CN}}$ values for a sigma bond. Mixing times in excess of $7 \mathrm{~ms}$ and an increased ${ }^{13} \mathrm{C}$ enrichment level $(>25 \%)$ are proposed to overcome the difficulty of observing the scalar transfer, but the presence of proton-assisted polarization transfer is a complicating factor in this sample. In the absence of protons, this mechanism is not available and, for aprotic network solids, APHH-CP at $n=0$ has considerable potential.

The problem of observing an NMR signal for a nucleus dipolar coupled to one or more unpaired electrons has been discussed by Nayeem et al., ${ }^{34}$ who showed that the interaction is inhomogeneous even in the presence of dipolar coupled, unpaired electrons, but only if the $g$-anisotropy is large. Such an interaction was observed for proton-electron pairs ${ }^{34}$ but also in ${ }^{13} \mathrm{C}$ spectra by Pan et al., who observed spinning sidebands over a 2000 ppm range in amorphous carbon. ${ }^{16}$ Extended spinning sideband manifolds were not observed in the ${ }^{13} \mathrm{C}$ or ${ }^{15} \mathrm{~N}$ spectra of our compounds, in agreement with our direct observation of minimal $g$-anisotropy. The observation of a single, almost featureless EPR line leaves open the possibility of free electrons localized on carbons instead of nitrogens, for which a substantial hyperfine coupling, resulting in typical three line $\left({ }^{14} \mathrm{~N}\right)$ or two line $\left({ }^{15} \mathrm{~N}\right)$ splittings up to $30 \mathrm{G}$, is usually expected (see refs 35 and 36 and references therein). ${ }^{15}$ The narrow observed EPR line width can be due either to small hyperfine couplings or to electron exchange (see ref 36, p 199). Although the ${ }^{15} \mathrm{~N}$ NMR spectra suggest free electrons localized on nitrogens, the EPR spectra do not unambiguously support this assignment. ${ }^{15} \mathrm{~N}$ ENDOR experiments are required to resolve this disparity.

Finally, we evaluate the potential for magnetic resonance data to provide a set of structural criteria in the bulk material that may determine the suitability of such samples as possible precursors for high-dimensional, $\mathrm{sp}^{3}$-hybridized, carbonnitrogen network solids. The temperature-pressure composition diagram of a similarly prepared sample has been previously reported ${ }^{19}$ in which it was found that kinetic decomposition to form $\mathrm{N}_{2}$ gas was favored over thermodynamic conversion of $\mathrm{sp}^{2}$ to $\mathrm{sp}^{3}$-carbon, even at very high temperatures and pressures. Such a material is unsuitable as a precursor for network bonded, covalent $\mathrm{CN}$ solids so long as the decomposition to $\mathrm{N}_{2}$ remains favored. Both NMR and EPR data suggest means by which a paracyanogen-like material can be tested for suitability for highpressure and high-temperature composition analyses. The line at $101 \mathrm{ppm}$ in the ${ }^{15} \mathrm{~N}$ spectra indicates $\mathrm{N}-\mathrm{N}$ bonds that can condense to $\mathrm{N}_{2}$ during decomposition. Synthetic preparations can be attempted to minimize this feature. Similarly, elimination of cyano groups removes $\mathrm{sp}^{1}$ carbon from the sample and may assist in favoring the thermodynamic process over the kinetic one. Monitoring the appropriate lines in the ${ }^{13} \mathrm{C}$ and ${ }^{15} \mathrm{~N}$ spectra will report on the relative cyano concentrations in the bulk. Of course, observation of ${ }^{13} \mathrm{C}$ signals in the $\mathrm{sp}^{3}$ region would be valuable. The presence of directly bound protons can be tested with simple cross-polarization build-up experiments, as in this study, or with dipolar dephasing or separated local field spectroscopies (for a recent review, see ref 12, Schmidt-Rohr and Spiess, pp 205-235).

Additionally, preliminary ${ }^{13} \mathrm{C}$ electron-nuclear doubleresonance (ENDOR) experiments have been performed at low temperature which reveals a complex distribution of dipolar couplings. Detailed modeling of this distribution may lead to a measure of the proximity of ${ }^{13} \mathrm{C}$ to paramagnetic centers.

Using NMR and EPR to provide feedback data versus variations in the synthetic parameters leading to $\mathrm{CN}$-polymers, it may be possible to develop a paracyanogen-like material with minimal N-N bonding, reduced hydrogenation, and greater $\mathrm{sp}^{3}$ character, and thus whose temperature/pressure composition diagram may favor thermodynamic rearrangement over kinetic decomposition. 


\section{Conclusion}

We have performed a study of an isotopically enriched, paracyanogen-like solid, which possesses relatively short relaxation times and resolved spectral regions. These spectral characteristics permitted the use of adiabatic-passage Hartmann-Hahn $\mathrm{CP}$ between ${ }^{13} \mathrm{C}$ and ${ }^{15} \mathrm{~N}$ to identify and assign three carbon sites and four nitrogen sites. We find that APHH$\mathrm{CP}$ is a robust recoupling method for network $\mathrm{CN}$ solids, providing information not readily available in conventional direct-excitation spectra while avoiding costly 2D experiments. We also showed the existence of two NH moieties by CP buildup experiments and note that preparations of $\mathrm{pCN}$-like solids, whether by RF sputtering or thermal annealing, seem to be susceptible to hydrogenation mechanisms. Although we are not able to unambiguously determine the local structure of this $\mathrm{pCN}$ like solid, we have demonstrated that water molecules do not add accross $\mathrm{C}=\mathrm{N}$ double bonds, confirmed the presence of nitrile groups, provided evidence for $\mathrm{N}-\mathrm{N}$ bonding, and shown the existence of paramagnetic centers. In particular, we note that the good resolution of many spectral regions is difficult to reconcile for an amorphous solid. Thus, in consideration of a rapidly declining spectral density, we propose that a repeated, two-dimensional structural motif exists with three-dimensional cross-linking. Finally, we have described methods that may permit the optimization of amorphous $\mathrm{CN}$ materials for hightemperature, high-pressure composition analyses.

Acknowledgment. We are grateful to Dr. Gang Wu and Dr. Phil Costa for advice and discussions during the project and to Chad Rienstra for guidance in the construction of the transmission line probes. Additional support from Prof. Charles Lieber is gratefully acknowledged.

\section{References and Notes}

(1) Cohen, M. L. Mater. Sci. Eng. 1996, A209, 1.

(2) Liu, A. Y.; Cohen, M. L. Science 1989, 245, 841.

(3) Liu, A. Y.; Cohen, M. L. Phys. Rev. B 1990, 41, 10727.

(4) Niu, C.; Lu, Y. Z.; Lieber, C. M. Science 1993, 261, 334-337.

(5) Kouvetakis, J.; Bandari, A.; Todd, M.; Wilkens, B. Chem. Mater. 1996, 6, 811-814.

(6) Merchant, A. R.; McColluch, D. G.; McKenxie, D. R.; Yin, Y.; Hall, L. J. Appl. Phys. 1996, 79(9), 6914.

(7) Xin, H.; Lin, C.; Xu, W.; Wang, L.; Zou, S.; Wu, X.; Shi, X.; Shu, H. J. Appl. Phys. 1996, 79(5), 2364.
(8) Fernandez, A.; Prieto, P.; Quiros, C.; Sanz, J. M.; Martin, J.-M.; Vacher, B. Appl. Phys. Lett. 1996, 69(6), 764.

(9) Husein, I. F.; Zhou, Y.; Li, F.; Allen, R. C.; Chan, C.; Kleiman, J. I. Mater. Sci. Eng. 1996, A209, 10.

(10) Tabbal, M.; Merel, P.; Moisa, S.; Chaker, M.; Ricard, A.; Moisan, M. Appl. Phys. Lett. 1996, 69(12), 1698.

(11) Mehring, M. Principles of High-Resolution NMR in Solids. 2nd ed.; Springer-Verlag: New York, 1983.

(12) Schmidt-Rohr, K.; Spiess, H. W. Multidimensional Solid-State NMR and Polymers; Academic Press: New York, 1994.

(13) Baldus, M. A. Ph.D. Dissertation, Eidgenossische Technische Hochschule, Zurich, 1996.

(14) Baldus, M.; Geurts, D. G.; Hediger, S.; Meier, B. H. J. Magn. Reson. A. 1996, 118, 140-144.

(15) Duijvestijn, M. J.; Van Der Lugt, C.; Smidt, J.; Wind, R. A.; Zilm, K. W.; Staplin, D. C. Chem. Phys. Lett. 1983, 102(1), 25.

(16) Pan, H.; Pruski, M.; Gerstein, B. C.; Li, F.; Lannin, J. S. Phys Rev B. 1991, 44(15), 6741-6745.

(17) Hall, D.; Maus, D. A.; Gerfen, G. J.; Inati, S. J.; Becerra, L. R.; Dahlquist, F. W.; Griffin, R. G. Science 1997, 276, 930-932.

(18) Abragam, A. The Principles of Nuclear Magnetism; University Press: London, 1961; Ch. 9.

(19) Stevens, A. J.; Koga, T.; Agee, C. B.; Aziz, M. J.; Lieber, C. M. J. Am. Chem. Soc. 1996, 118, 10900.

(20) Bennati, M.; et al. J. Magn. Reson. 1999, 138, 232-243.

(21) Gay-Lussac, L. J. Ann. Chim. (Paris) 1815, 95, 175.

(22) Jenneskens, L. W.; Mahy, J. W. G.; Vlietstra, E. J.; Goede, S. J.; Bickelhaupt, F. J. Chem. Soc., Faraday Trans. 1994, 90, 327.

(23) Maya, L. J. Polym. Sci. A: Polym. Chem. 1993, 31, 2595.

(24) Stoll, E.; Vaughan, R. W.; Saillant, R. B.; Cole, T. J. Chem. Phys. 1974, 61(7), 2896-2899.

(25) Harris, R. K.; Leach, M. J. Chem. Mater. 1990, 2, 320-323.

(26) Wu, X.; Zilm, K. W. J. Magn. Reson. A. 1993, 102, 205. 29.

(28) Harris, R. K.; Leach, M. J. Chem. Mater. 1992, 4, 260-267.

(29) Leone, E. A.; Curran, S.; Kotun, M. E. J. Am. Ceram. Soc. 1996, $79(2), 513$.

(30) Kaplan, S.; Jansen, F.; Machonkin, M. Appl. Phys. Lett. 1985, 47, 750.

(31) Beamson, G.; Brennan, W. J.; Clayden, N. J.; Jennings, R. C. K. J. Polym. Sci.: Part B: Polym. Phys. 1993, 31, 1205.

(32) Ricci, M.; et al. J. Mater. Res. 1993, 8(3), 480-488.

(33) Duncan, T. M. A Compilation of Chemical Shift Anisotropies: Farragut Press: Chicago, 1990.

(34) Nayeem, A.; Yesinowski, J. J. Chem. Phys. 1988, 89, 4600.

(35) Poole, C. P. Electron Spin Resonance, 2nd ed.; Dover Publications: Mineola, New York, 1983.

(36) Carrington, A.; McLachlan, A. D. Introduction to Magnetic Resonance; Harper \& Row: New York, 1967.

(37) Brotherton, T. K.; Lynn, J. W. Chem. Rev. 1959, 59, 841. 